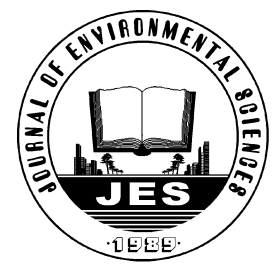

\title{
Polybrominated diphenyl ethers in soil from three typical industrial areas in Beijing, China
}

\author{
Yongfei Zhang ${ }^{1}$, Shan $\mathrm{Fu}^{1, *}$, Xinchun $\mathrm{Liu}^{2, *}$, Zheng $\mathrm{Li}^{1}$, Yuan Dong ${ }^{1}$ \\ 1. State Key Laboratory of Environmental Chemistry and Ecotoxicology, Research Center for Eco-Environmental Sciences, \\ Chinese Academy of Sciences, Beijing 100085, China. E-mail: fyzhang0112@126.com \\ 2. University of Chinese Academy of Sciences, Beijing 100049, China
}

Received 27 February 2013; revised 02 April 2013; accepted 21 May 2013

\begin{abstract}
Areas containing industrial facilities belonging to three different typical industries that may cause pollution by polybrominated diphenyl ethers (PBDEs) in Beijing, China were investigated. Specifically, the areas contained a solid waste incineration plant, a chemical factory, and a heat and power plant. Investigation of the pollution status of PBDEs in the surface soil from areas around these industries revealed the highest concentration of 42 PBDE congeners $(118 \mathrm{ng} / \mathrm{g}$, dry mass) at the solid waste incineration plant. In the other two plants, the highest concentrations were both $26 \mathrm{ng} / \mathrm{g}$ (dry mass). Among the PBDE homologues, the PBDE contamination at all sites showed similar congener compositions, with BDE 209 being the dominant congener. Our findings established the first contamination status of three typical industrial areas in Beijing. Furthermore, the total concentrations of $42 \mathrm{PBDE}$ congeners tended to decrease as the distance from the investigated plants increased. Overall, these plants were identified as potential pollution sources of PBDEs in Beijing. Moreover, Pearson correlation analysis revealed that the major PBDE source in Beijing may be associated with the technical deca-BDE and penta-BDE mixture. Based on the data obtained in this preliminary investigation, further study of the potential of these sources to emit PBDEs in Beijing is warranted.
\end{abstract}

Key words: different industry areas; pollution source; polybrominated diphenyl ethers; soil

DOI: $10.1016 / \mathrm{S} 1001-0742(12) 60332-5$

\section{Introduction}

Polybrominated diphenyl ethers (PBDEs) have been used as brominated flame retardants since the 1960s because of their high thermal stability and low cost (Jiang et al., 2012; Li et al., 2012). As a result, PBDEs have been added to many consumer products including textiles, rubber materials, and electronic products (Dodder et al., 2012; Kang et al., 2011). However, PBDEs do not bind chemically to these products and accordingly, they may leak continuously to the environment during use of the products to which they are added (Sühring et al., 2013; Wang et al., 2011; Wei et al., 2012). PBDEs can also bioaccumulate, biomagnify and undergo long-range transport to remote ecosystems (Agrell et al., 2004). Many studies have shown that PBDEs harm human health and cause many environmental problems. There is also evidence that they act as thyroid hormone disrupters, cause neurological damage in neonatal mammals, and have long-term conse-

\footnotetext{
* Corresponding author. E-mail: fushan@rcees.ac.cn (Shan Fu), xcliu@ucas.ac.cn (Xinchan Liu)
}

quences on motor behavior and learning capacity. Meeker et al. (2009) investigated the relationship between PBDE concentrations in house dust and hormone levels in men and found that dust PBDE concentrations were strongly and inversely associated with luteinizing hormones and follicle stimulating hormones.

In general, PBDEs comprise 209 different brominated diphenylether congeners (Cunha et al., 2010). Commercial flame retardants are mixtures of only three major products, octa-, penta-, and deca-BDE, which contain a defined number of congeners. Due to their adverse effects on the environment and human health, PBDEs have been banned from production and use in the European Union (EU). Moreover, congeners used in technical penta- and octaBDE mixtures have officially been classified as persistent organic pollutants (POPs) under the Stockholm Convention.

Since PBDEs were first detected in Sweden in fish samples taken downstream from several textile industries on the River Viskan (de Cynthia, 2002), they have been found in abiotic matrices, such as soils, sediments, aquatic 
systems and the atmosphere (An et al., 2011; Cunha et al., 2010; Hu et al., 2010; Li et al., 2012; Wang et al., 2009; Zhao et al., 2009). PBDEs are also widespread in the biotic environment and have been found in human hair, fish, cow's milk, etc. (Echols et al., 2013; Kang et al., 2011; Lake et al., 2013; Qin et al., 2011). Many investigations of the pollution sources that can cause PBDE contamination have been conducted, with electronic waste (e-waste) recycling areas being the most commonly studied (Agrell et al., 2004; An et al., 2011; Huang et al., 2011; Wang et al., 2011; Xu et al., 2009). However, few investigations of point sources such as factories that may cause PBDE pollution have been conducted to date. Since such factories are often located next to residential areas, pollution from these facilities can lead to serious health problems. Therefore, it is important to obtain as much information pertaining to the distribution of PBDEs in these areas as possible.

Beijing, China has a long history of industrial activity: iron and steel industry, coal-fired power plants, and chemical plants. Recent rapid economic growth and urbanization have led to a great increase in pollution and a series of pollution problems. Thus, it is necessary to immediately investigate the current contamination status of this key urban area in China.

In this study, we selected three potential pollution sources and analyzed the concentrations of PBDEs in the surrounding soils. Specifically, we investigated a solid waste incineration plant, a chemical plant, and a heat and power plant. The main objectives of this study were to establish the contamination status, explore the interaction of PBDEs from different industries in the soil, and identify possible sources of pollution.

\section{Materials and methods}

\subsection{Samples}

We collected 32 soil samples from three industrial areas located in Beijing, China, which has a population of over 10,000,000 people (Fig. 1). The solid waste incineration plant is the first and largest incineration plant in the city, and more than 3000 tons of wastes are delivered to this plant each day. The pollution source sampling site was

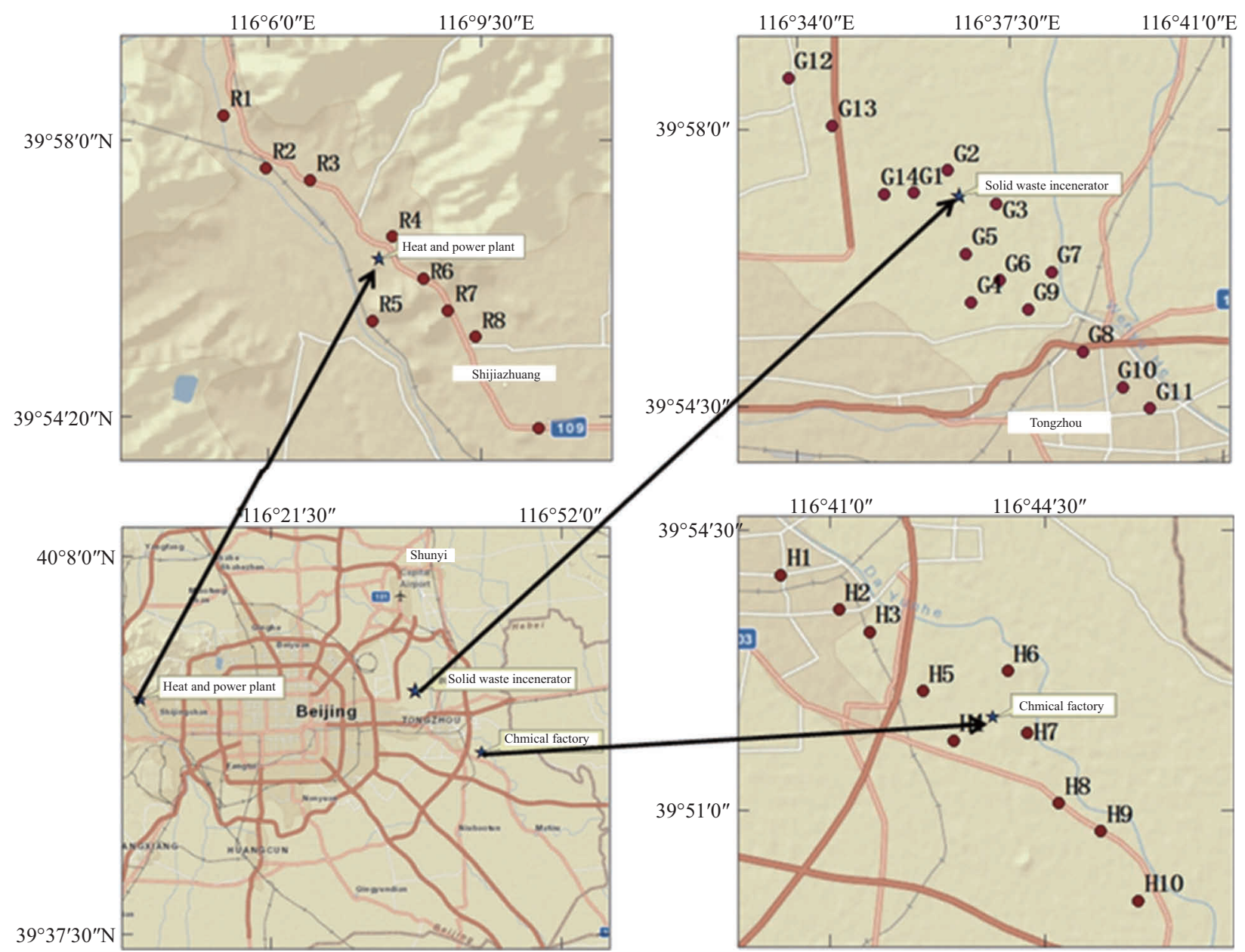

Fig. 1 Sampling sites (heat and power plant R1-R9, solid waste incinerator plant G1-G14, chemical factory H1-H10) of three typical industrial areas in Beijing. 
located close to the incineration building, while the other sampling sites were set about $1-5 \mathrm{~km}$ away from the plant. The sampling sites were distributed from northwest to southeast, in accordance with the main wind direction in the city. The chemical factory has been in operation since 1978; it covers an area of 128 ha, and is the largest producer of acrylic acid in China. The heat and power plant is located in the northwest portion of the city, with an installed capacity of $660 \mathrm{MW}$. The sampling locations in these two industrial areas were similar to those for the incineration plant (Fig. 1).

At each sampling point, we collected five surface soil samples $(0-10 \mathrm{~cm}$ in depth) in a square area $100 \mathrm{~m}$ by 100 $\mathrm{m}$, and then mixed them in equal mass. The samples were then freeze-dried and sifted through a 2-mm mesh. After these processes were completed, we put the soil samples in brown glass bottles and kept them at $-20^{\circ} \mathrm{C}$.

\subsection{Chemicals}

A standard solution of 39 PBDE congeners (EPA method 1614 standard solution) (AccuStandard, New Haven, CT, USA) was used to quantify the following congeners: mono-BDEs 1, 2 and 3; di-BDEs 7, 8, 10, 11, 12, 13, and 15 ; tri-BDEs $17,25,28,30,32,33,35$, and 37 ; tetra-BDEs $47,49,66,71,75$, and 77 ; penta-BDEs 85 , 99, 100, 116, 118, 119, and 126; hexa-BDEs 138, 153, 154, 155, and 166; and hepta-BDEs 181, 183, and 190. An analytical standard of BDE-205, 206, and 209 was purchased from AccuStandard Corporation. ${ }^{13} \mathrm{C}$-labled BDE-47, 99, 183 and 209 (Cambridge Isotope Laboratory, Andover, MA, USA) were used as a surrogate standard. $n$-Hexane, dichloromethane, and toluene were pesticide grade (Fisher Scientific, Fair Lawn, USA), while nonane was GC grade (Fluka, Sigma-Aldrich Chemie GmbH, Germany). Anhydrous sodium sulfate, sodium hydroxide, silver nitrate and sulfuric acid were guaranteed reagents (Sinopharm Chemical Reagent Corporation, China). Silica was analytical grade (Qingdao Haiyang Chemical Corporation, China) for chromatography with size 60-100 mesh.

\subsection{Extraction and cleanup}

Five grams of each soil sample were weighed and then homogenized with anhydrous sodium sulfate to produce a free-flowing powder. Before extraction, $50 \mu \mathrm{L}$ of ${ }^{13} \mathrm{C}$ BDE-47, 99, 183 and 209 (all at $100 \mathrm{ng} / \mathrm{mL}$ ) was added to each sample as a surrogate standard and balanced in a desiccator for $2 \mathrm{hr}$. PBDEs in these samples were then extracted with $40 \mathrm{~mL}$ of hexane and dichloromethane $(1: 1, V / V)$ using an ultrasonic wave for $3 \mathrm{~min}$ and then centrifuged at $3500 \mathrm{r} / \mathrm{min}$. This process was repeated three times, after which extracts were combined. The extracts were then concentrated to approximately $2 \mathrm{~mL}$ with a rotary vacuum evaporator for cleanup, which was conducted using the methods described in our previous report ( $\mathrm{Li}$ et al., 2008).

\subsection{Sample analysis}

The extracts were analyzed on an Agilent 6890 series gas chromatograph (Agilent Technologies, USA) coupled to an Agilent 5973 mass spectrometer (Agilent Technologies, USA) using negative chemical ionization (NCI) in selected ion monitoring mode. The MS source temperature was $150^{\circ} \mathrm{C}$, and the electron energy was $70 \mathrm{eV}$. The GC was equipped with a splitless injector (7683B, Agilent Technologies, USA) which was held at a constant temperature of $270^{\circ} \mathrm{C}$. Gas chromatographic separation was performed on a $15 \mathrm{~m}$ DB-5MS capillary column $(15 \mathrm{~m} \times 0.25$ $\mathrm{mm}$ internal diameter; $0.25 \mathrm{~mm}$ film thickness) (Agilent Technologies, USA). We maintained the GC column at $80^{\circ} \mathrm{C}$ for $1 \mathrm{~min}$ and then increased the temperature at $10^{\circ} \mathrm{C} / \mathrm{min}$ to $200^{\circ} \mathrm{C}$, after which it was ramped at $20^{\circ} \mathrm{C} / \mathrm{min}$ to $300^{\circ} \mathrm{C}$, where it was held for $5 \mathrm{~min}$. The compounds were monitored at $\mathrm{m} / \mathrm{z}, 79$ and 81 for PBDE congeners other than BDE-47, 99, 183, 209, and the ${ }^{13} \mathrm{C}$-labeled BDEs. These congeners were monitored at $\mathrm{m} / \mathrm{z} 325$ and 327 (for BDE-47), 404 and 406 (for BDE-99), 562 and 564 (for BDE-183), 487 and 489 (for BDE-209), 337 and 339 (for ${ }^{13} \mathrm{C}-\mathrm{BDE}-47$ ), 415 and 417 (for $\left.{ }^{13} \mathrm{C}-\mathrm{BDE}-99\right), 574$ and 578 (for ${ }^{13} \mathrm{C}-\mathrm{BDE}-183$ ), and 493 and 495 (for ${ }^{13} \mathrm{C}-\mathrm{BDE}-$ 209).

\subsection{Quality control and quality assurance}

To avoid sample contamination, cross contamination, and PBDE degradation, we adopted appropriate measures during sample collection and chemical analysis. All samples were spiked with surrogate standards of ${ }^{13} \mathrm{C}$-labeled BDE47, 99, 183, and 209 to monitor the analyte losses. The recoveries of ${ }^{13} \mathrm{C}-\mathrm{BDE}-47,{ }^{13} \mathrm{C}-\mathrm{BDE}-99,{ }^{13} \mathrm{C}-\mathrm{BDE}-183$ and ${ }^{13} \mathrm{C}-\mathrm{BDE}-209$ ranged from $64 \%-127 \%, 79 \%-117 \%$, $58 \%-104 \%$ and $51 \%-108 \%$, respectively. The limits of detection (LOD) were defined as a signal-to-noise ratio of 3:1. The LOD of individual PBDEs ranged from 0.03 to $0.84 \mathrm{ng} / \mathrm{g}$.

\section{Results and discussion}

\subsection{PBDEs in soil}

The concentrations of PBDEs in the soil samples around these three areas are shown in Table 1. The detection rates of PBDEs in the soil samples reached $100 \%$, which indicated that they were widespread around these areas. The total PBDE concentrations (defined as the sum of 42 congeners) were $0.24 \mathrm{ng} / \mathrm{g}-1.2 \times 10^{2} \mathrm{ng} / \mathrm{g}$ with a mean of $8.5 \mathrm{ng} / \mathrm{g}$.

The highest level was found at G2 $\left(1.2 \times 10^{2} \mathrm{ng} / \mathrm{g}\right.$ dry mass), which was five times higher than the highest levels at the other two industrial areas. This profile may have been due to the wide variety of municipal solid waste at this location, especially e-waste. When compared to the chemical factory and power plant, the disposal of PBDEs 
Table 1 PBDEs concentrations (ng/g dry mass) in soil samples

\begin{tabular}{|c|c|c|c|c|c|c|c|c|c|}
\hline Sampling site & mono-BDEs & tri-BDEs & tetra-BDEs & penta-BDEs & hexa-BDEs & hepta-BDEs & nona-BDEs & BDE-209 & $\sum_{42} \mathrm{PBDEs}$ \\
\hline \multicolumn{10}{|c|}{ Solid waste incineration plant } \\
\hline G1 & 0.01 & 0.02 & 0.36 & 4.9 & 0.08 & 0.05 & 0.26 & 5.30 & 11 \\
\hline $\mathrm{G} 2$ & 0.02 & 0.03 & 0.11 & 0.56 & 0.34 & 0.33 & 1.6 & $1.2 \times 10^{2}$ & $1.2 \times 10^{2}$ \\
\hline G3 & 0.03 & N.D. & 0.14 & 0.39 & 0.01 & 0.01 & 0.02 & 0.08 & 0.68 \\
\hline G4 & N.D. & 0.01 & 0.02 & 0.23 & N.D. & N.D. & N.D. & 0.02 & 0.29 \\
\hline G5 & N.D. & 0.01 & 0.03 & 0.36 & 0.01 & 0.01 & 0.04 & 0.46 & 0.92 \\
\hline G6 & N.D. & N.D. & 0.18 & 1.1 & 0.01 & 0.01 & 0.03 & 0.08 & 1.4 \\
\hline G7 & 0.04 & 0.12 & 0.11 & 0.03 & 0.01 & 0.02 & N.D. & 0.08 & 0.42 \\
\hline G8 & 0.25 & 0.04 & 0.33 & 22 & 0.07 & 0.07 & 0.04 & 1.0 & 24 \\
\hline G9 & 0.21 & 0.01 & 0.03 & 0.69 & 0.01 & 0.02 & 0.03 & 0.29 & 1.3 \\
\hline G10 & N.D. & 0.01 & 0.03 & 1.4 & 0.02 & 0.01 & 0.03 & 0.23 & 1.8 \\
\hline G11 & 0.01 & N.D. & 0.33 & 0.14 & N.D. & N.D. & N.D. & N.D. & 0.48 \\
\hline G12 & N.D. & 0.02 & 0.17 & 1.4 & 0.02 & 0.01 & 0.03 & 0.43 & 2.1 \\
\hline G13 & 0.01 & 0.01 & 0.05 & 0.18 & 0.01 & 0.03 & N.D. & 0.05 & 0.35 \\
\hline G14 & 0.01 & 0.01 & 0.64 & 0.19 & 0.06 & 0.06 & 0.16 & 1.9 & 3.0 \\
\hline \multicolumn{10}{|c|}{ Chemical factory } \\
\hline $\mathrm{H} 1$ & 0.03 & 0.02 & 0.10 & 11 & 0.04 & 0.04 & 0.19 & 11 & 22 \\
\hline $\mathrm{H} 2$ & 0.02 & 0.06 & 0.23 & 3.2 & 0.03 & 0.03 & 0.14 & 3.3 & 6.9 \\
\hline H3 & 0.01 & 0.18 & 0.20 & 1.4 & 0.05 & 0.03 & 0.05 & 2.0 & 3.9 \\
\hline $\mathrm{H} 4$ & 0.01 & 0.06 & 0.17 & 1.9 & 0.07 & 0.07 & 0.20 & 4.3 & 6.9 \\
\hline H5 & 0.01 & 0.03 & 0.19 & 0.31 & 0.04 & 0.05 & 0.32 & 25 & 26 \\
\hline H6 & 0.02 & 0.16 & 0.25 & 0.53 & 0.12 & 0.09 & N.D. & 0.63 & 1.8 \\
\hline $\mathrm{H} 7$ & 0.55 & 0.01 & 2.2 & 0.10 & 0.01 & 0.01 & N.D. & 0.03 & 2.9 \\
\hline H8 & 0.04 & 0.01 & 0.05 & 0.30 & 0.01 & 0.01 & 0.04 & 0.40 & 0.87 \\
\hline H9 & 0.01 & 0.30 & 0.49 & 0.08 & 0.01 & N.D. & N.D. & 0.02 & 0.92 \\
\hline H10 & 0.01 & 0.04 & 0.09 & 0.29 & 0.03 & 0.02 & 0.11 & 2.9 & 3.5 \\
\hline \multicolumn{10}{|c|}{ Heat and power plant } \\
\hline $\mathrm{R} 1$ & 0.01 & N.D. & 0.13 & 0.10 & N.D. & N.D. & N.D. & N.D. & 0.24 \\
\hline $\mathrm{R} 2$ & 0.01 & 0.01 & 0.04 & 0.14 & 0.01 & 0.01 & 0.01 & 0.03 & 0.26 \\
\hline $\mathrm{R} 3$ & 0.02 & 0.03 & 0.11 & 0.08 & 0.05 & 0.06 & 0.11 & 25 & 26 \\
\hline $\mathrm{R} 4$ & 0.03 & 0.10 & 0.10 & 0.42 & 0.09 & 0.04 & N.D. & 0.11 & 0.89 \\
\hline R5 & 0.02 & 0.06 & 0.44 & 0.35 & 0.06 & 0.05 & N.D. & N.D. & 0.99 \\
\hline R6 & 0.03 & 0.05 & 0.06 & 0.25 & 0.01 & 0.01 & 0.04 & 0.10 & 0.54 \\
\hline R7 & 0.04 & 0.05 & 0.03 & 0.17 & 0.01 & 0.01 & 0.06 & 0.19 & 0.56 \\
\hline $\mathrm{R} 8$ & 0.02 & N.D. & 0.17 & 0.23 & 0.04 & 0.02 & N.D. & N.D. & 0.48 \\
\hline
\end{tabular}

N.D. was calculated assuming non-detected measurements were equal to LOD.

Data with gray backgrounds represent the highest concentrations for each industry.

at the incineration plant is more extensive. In solid waste, PBDEs are ubiquitous, especially in electronics waste, and it has been shown that a large amount of PBDEs leak out to the environment when these materials are burned (Agrell et al., 2004; Wang et al., 2010a, 2010b). Pollution levels among industries were compared using the MannWhitney $U$-test to analyze PBDEs; however, no significant differences were observed among these industries. However, the concentration of PBDEs in soils collected from areas representing all three industries was much higher than the background level in the soils of a large city. For example, the PBDE concentrations in soils of Shanghai range from 0.13 to $1.2 \mathrm{ng} / \mathrm{g}$ (Jiang et al., 2012). Overall, these findings indicate that the industries investigated in this study might be PBDE pollution sources. The highest concentration $\left(1.2 \times 10^{2} \mathrm{ng} / \mathrm{g}\right)$ was comparable to the pollution level in industrial areas of the Shenzhen, which has a median concentration of $346 \mathrm{ng} / \mathrm{g}$ (Qin et al., 2011; Xu et al., 2009; Zhang et al., 2012).
The concentrations of PBDEs at each site are shown in Fig. 2. We also found that the concentrations of PBDEs decreased with increasing distance from the pollution source (Fig. 3). The PBDE concentrations detected at the farthest site $(0.35,0.92,0.23 \mathrm{ng} / \mathrm{g})$ away from the three point pollution sources were equal to or higher than the concentrations in soils collected from urban Shanghai $(0.4$ $\mathrm{ng} / \mathrm{g}$ ) (Jiang et al., 2012), indicating that PBDE contamination caused by these point pollution sources contaminated the whole area through a halo effect (Macdonald et al., 2000; Stow et al., 2005).

The highest levels of PBDEs contamination at all three pollution sources were northwest of the plants. This may have occurred as a result of the primary wind direction in this city when we collected these samples.

\subsection{PBDE homologues}

Of the PBDE homologues, the dominant PBDE detected from soil was BDE-209 (median: 38\%), followed by 


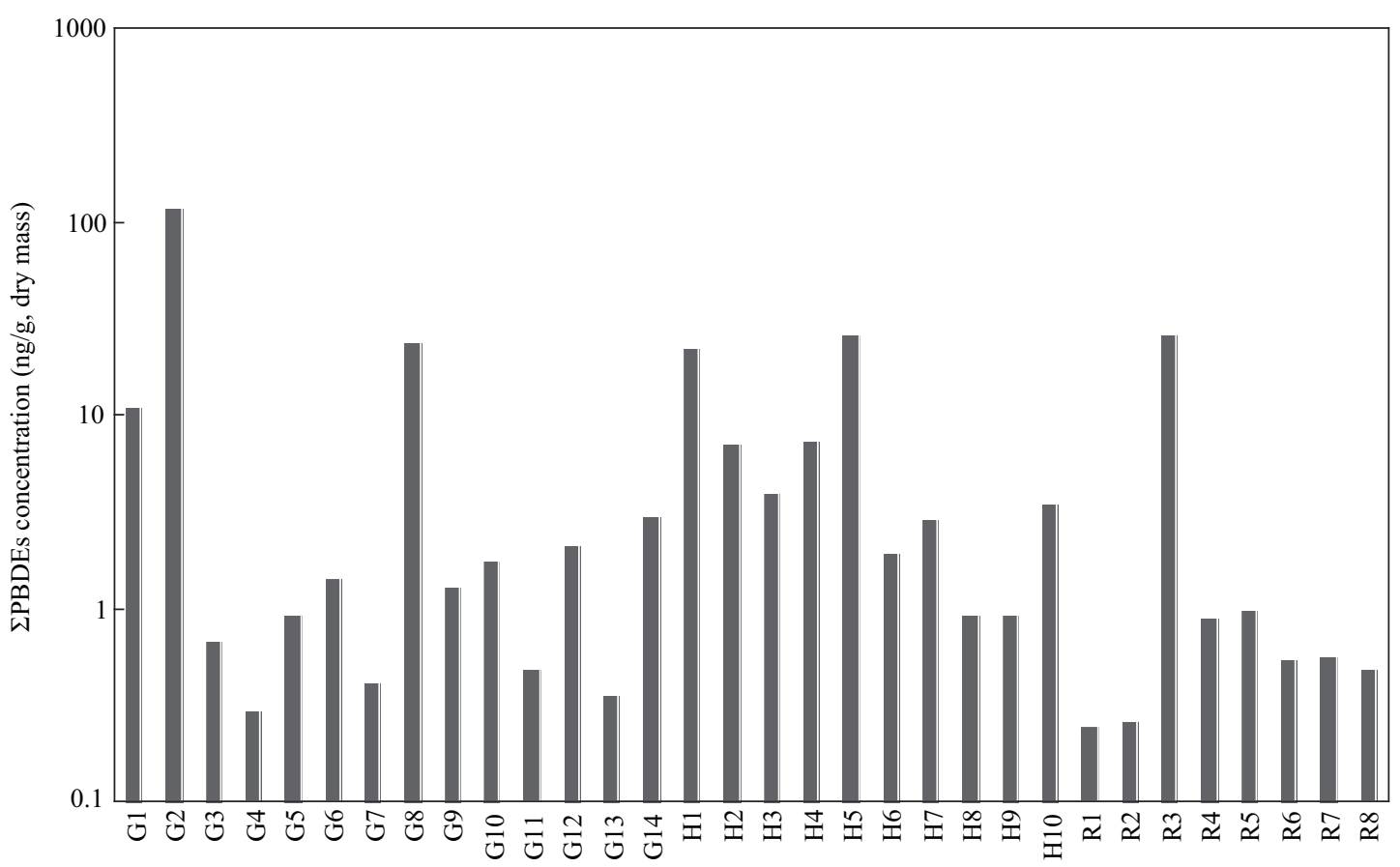

Fig. 2 Concentration of PBDEs in the soil of three typical industrial areas.

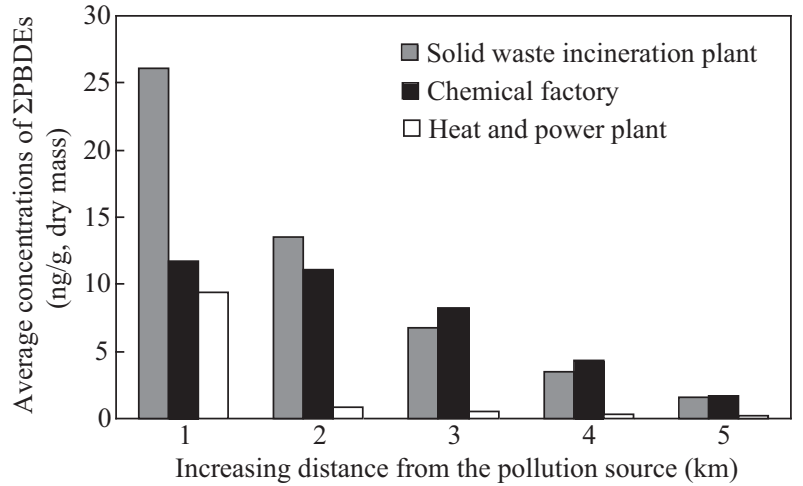

Fig. 3 Distribution of PBDEs in the soil of three typical industrial areas.

penta-BDEs and tetra-BDEs (medians: $32 \%$ and $24 \%$, respectively; Fig. 4). This profile is reasonable since higher-brominated congeners are firmly bound to particles due to their low volatility (Palm et al., 2002).

The domestic production and demand for PBDEs in China is enormous, and the predominantly used product is deca-BDE $(30,000$ metric tons in 2005), followed by octaBDE and penta-BDE (Zhou et al., 2012). Accordingly, these results may also be caused by the predominant use of the deca-BDE mixture in China.

To investigate the characteristics of the different industrial areas, the concentrations of different congeners in each area were compared (Fig. 5). The predominant congeners were tetra-, penta-BDEs and BDE-209 in all areas, and all were present in approximately equal concentrations.

The concentrations of BDE-209 in the soil samples also showed an inverse relationship with distance from the pollution sources (Table 1). The concentration of BDE209 in the area of the pollution source was much higher than in areas farther away. The highest levels of BDE209 contamination were observed in close proximity to the plant, and the concentrations were 100 times higher than at sites far away from the pollution sources. When compared to the urban soil level $(0.25 \mathrm{ng} / \mathrm{g})$ of BDE-209 in Shanghai (Jiang et al., 2012), the concentrations of BDE209 in the soil samples collected from $5 \mathrm{~km}$ away from the industrial areas investigated in the present study were at the background level. Additionally, the pollution levels of these plants were not as serious as in the e-waste areas (Zhao et al., 2009), and the halo effects of these pollution sources were much lower than those of the e-waste sites. However, it is obvious that these plants were pollution sources of BDE-209. Moreover, all were located close to residential areas, so they should be studied further.

The other general BDE congeners observed with high detection rates $(>69 \%)$ were BDE-47 and BDE-99. The concentrations of these two congeners ranged from not detectable to $2.17 \mathrm{ng} / \mathrm{g}$ and not detectable to $21.8 \mathrm{ng} / \mathrm{g}$, respectively. Furthermore, the concentrations of these two congeners did not show an obvious decrease with distance. Finally, the concentrations of PBDEs and BDE-209 were both negatively correlated with distance. These findings indicate that the decrease of PBDEs with distance was mainly caused by BDE-209.

\subsection{PBDEs distribution characteristics}

There were some correlations between PBDEs and the distance from source pollution. The concentrations of PBDEs indicated that the source pollution area was the 


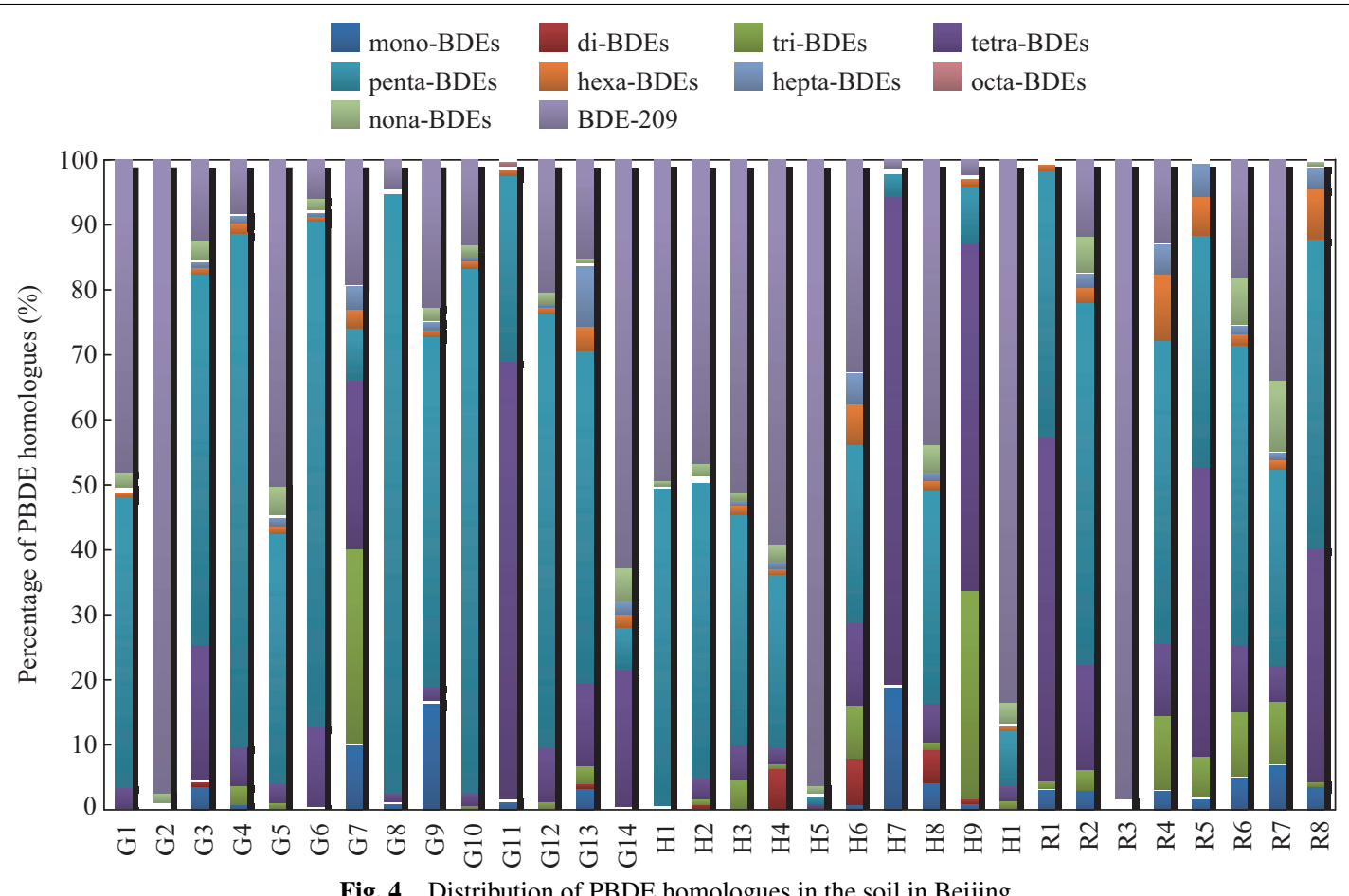

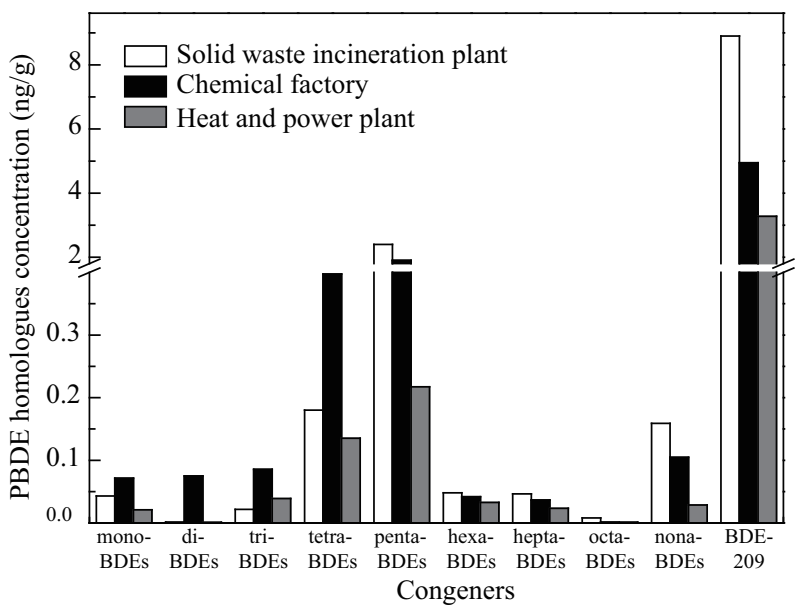

Fig. 5 Distribution of PBDE homologues from different typical industrial areas in Beijing.

most polluted area, and that concentration decreased with distance (Fig. 3). For BDE-47 and BDE-99, the differences in concentration might be neglected when accounting for distance.

As the distance from the pollution source increased, the concentrations of some congeners (hexa-, hepta-, octaand nona-BDEs) decreased. This may have been due to these four congeners not easily traveling long distances or to their degradation soon after being released from the factories. Among the PBDE homologues, BDE-209 was dominant in soil in this study. Thus, soil was not only an important sink but also a key source that influenced other environmental matrices.

\subsection{Source analysis}

We found that more than 3000 tons of solid wastes were delivered to this incinerator plant daily. A study conducted by Wang and Wang (2013) showed that combustible materials such as plastics, paper, textiles, wood and food waste accounted for $94.66 \%$ of municipal solid waste in Beijing. Flame retardants were added to most of these wastes, and PBDEs are a common flame retardant in China. During handling of these wastes, PBDEs can leak out into the environment and cause pollution.

Many of the products from the chemical factory were flammable; therefore flame retardants (especially PBDEs) were added to these products. As a result, the chemical factory also discharged waste gas and water containing PBDEs to the environment.

The heat and power plant can be regarded as a PBDE pollution source because of the equipment used in this facility. Safety is very important during the production in the plant so large amounts of flame retardant are generally necessary.

To analyze the potential sources and distribution of PBDEs, Pearson correlation analyses were performed for the main PBDEs congeners in the soil of these areas. The coefficients ranged from 0.002 (mono-BDEs vs. $\sum$ PBDE) to 0.98 (BDE-209 vs. $\sum$ PBDE). The close relationship between BDE-209 and $\sum$ PBDE indicated that BDE-209 was the predominant contaminant. These findings suggest that deca-BDE is the dominant technical formulation used in materials present in the industrial areas studied. The high correlation coefficients of hexa-BDEs versus hepta-BDEs, octa-BDEs, and deca-BDEs (0.799 to 0.977) 
indicated that they may have had a common source and similar environmental behavior. Besides BDE-209, the high concentrations of BDE-99 indicated that the pentaformulation was also ubiquitous in the three industrial areas.

\section{Conclusions}

In this study, PBDEs were detected in the areas surrounding three plants located near a residential district in Beijing, China. The concentrations were extremely high at locations sampled within the facilities. As the distance from the plants increased, the concentration of PBDEs (especially BDE-209) decreased. BDE-209 was the predominant contaminant in all sampled areas. Overall, the results of this study indicate that the three plants are potential pollution sources of PBDEs in Beijing. Since they were all very close to the residential district, greater attention should be given to contamination by these facilities due to the possible health hazards they pose.

\section{Acknowledgments}

This work was supported by the National Natural Science Foundation of China (No. 21177148).

\section{References}

Agrell C, Schure A F H, Sveder J, Bokenstrand A, Larsson P, Zegers B N, 2004. Polybrominated diphenyl ethers (PBDES) at a solid waste incineration plant I: Atmospheric concentrations. Atmospheric Environment, 38(30): 51395148.

An T C, Zhang D L, Li G Y, Mai B X, Fu J M, 2011. On-site and off-site atmospheric PBDEs in an electronic dismantling workshop in south China: Gas-particle partitioning and human exposure assessment. Environmental Pollution, 159(12): 3529-3535.

Cunha S C, Kalachova K, Pulkrabova J, Fernandes J O, Oliveira M B, Alves A et al., 2010. Polybrominated diphenyl ethers (PBDEs) contents in house and car dust of Portugal by pressurized liquid extraction (PLE) and gas chromatography-mass spectrometry (GC-MS). Chemosphere, 78(10): 1263-1271.

de Cynthia N W, 2002. An overview of brominated flame retardants in the environment. Chemosphere, 46(5): 583624.

Dodder N G, Maruya K A, Lauenstein G G, Ramirez J, Ritter K J, Schiff K C, 2012. Distribution and sources of polybrominated diphenyl ethers in the Southern California Bight. Environmental Toxicology and Chemistry, 31(10): 22392245.

Echols K R, Peterman P H, Hinck J E, Orazio C E, 2013. Polybrominated diphenyl ether metabolism in field collected fish from the Gila River, Arizona, USA-levels, possible sources, and patterns. Chemosphere, 90(1): 20-27.

Hu G C, Xu Z C, Dai J Y, Mai B X, Cao H, Wang J S et al., 2010. Distribution of polybrominated diphenyl ethers and decabromodiphenylethane in surface sediments from Fuhe River and Baiyangdian Lake, North China. Journal of Environmental Sciences, 22(12): 1833-1839.

Huang H L, Zhang S Z, Christie P, 2011. Plant uptake and dissipation of PBDEs in the soils of electronic waste recycling sites. Environmental Pollution, 159(1): 238-243.

Jiang Y F, Wang X T, Zhu K, Wu M H, Sheng G Y, Fu J M, 2012. Occurrence, compositional patterns, and possible sources of polybrominated diphenyl ethers in agricultural soil of Shanghai, China. Chemosphere, 89(8): 936-943.

Kang Y, Wang H S, Cheung K C, Wong M H, 2011. Polybrominated diphenyl ethers (PBDEs) in indoor dust and human hair. Atmospheric Environment, 45(14): 2386-2393.

Lake I R, Foxall C D, Fernandes A, Lewis M, Rose M, White O et al., 2013. Seasonal variations in the levels of PCDD/Fs, PCBs and PBDEs in cows' milk. Chemosphere, 90(1): 72 79.

Li K, Fu S, Yang Z Z, Xu X B, 2008. Composition, distribution and characterization of Polybrominated Diphenyl Ethers (PBDEs) in the Soil in Taiyuan, China. Bulletin of Environmental Contamination and Toxicology, 81(6): 588-593.

Li Y Y, Lin T, Chen Y J, Hu L M, Guo Z G, Zhang G, 2012. Polybrominated diphenyl ethers (PBDEs) in sediments of the coastal East China Sea: occurrence, distribution and mass inventory. Environmental Pollution, 171: 155-161.

Macdonald R W, Barrie L A, Bidleman T F, Diamond M L, Gregor D J, Semkin R G et al., 2000. Contaminants in the Canadian Arctic: 5 years of progress in understanding sources, occurrence and pathways. Science of the Total Environment, 254(2-3): 93-234.

Meeker J D, Johnson P I, Camann D, Hauser R, 2009. Polybrominated diphenyl ether (PBDE) concentrations in house dust are related to hormone levels in men. Science of the Total Environment, 407(10): 3425-3429.

Palm A, Cousins I T, Mackay D, Tysklind M, Metcalfe C, Alaee M, 2002. Assessing the environmental fate of chemicals of emerging concern: a case study of the polybrominated diphenyl ethers. Environmental Pollution, 117(2): 195-213.

Qin P H, Ni H G, Liu Y S, Shi Y H, Zeng H, 2011a. Occurrence, distribution, and source of polybrominated diphenyl ethers in soil and leaves from Shenzhen Special Economic Zone, China. Environmental Monitoring and Assessment, 174(14): 259-270

Qin X F, Qin Z F, Li Y, Zhao Y X, Xia X J, Yan S S et al., 2011b. Polybrominated diphenyl ethers in chicken tissues and eggs from an electronic waste recycling area in southeast China. Journal of Environmental Sciences, 23(1): 133-138.

Stow J P, Sova J, Reimer K J, 2005. The relative influence of distant and local (DEW-line) PCB sources in the Canadian Arctic. Science of the Total Environment, 342(1-3): 107118.

Sühring R, Möller A, Freese M, Pohlmann J D, Wolschke H, Sturm R et al., 2013. Brominated flame retardants and dechloranes in eels from German Rivers. Chemosphere, 90(1): 118-124

Wang H, Wang C M, 2013. Municipal solid waste management in Beijing: characteristics and challenges. Waste Management and Research , 31(1): 67-72.

Wang J X, Lin Z K, Lin K F, Wang C Y, Zhang W, Cui C Y et al., 
2011. Polybrominated diphenyl ethers in water, sediment, soil, and biological samples from different industrial areas in Zhejiang, China. Journal of Hazardous Materials, 197: 211-219.

Wang L C, Hsi H C, Wang Y F, Lin S L, Chang-Chien G P, 2010a. Distribution of polybrominated diphenyl ethers (PBDEs) and polybrominated dibenzo-p-dioxins and dibenzofurans $(\mathrm{PBDD} / \mathrm{Fs})$ in municipal solid waste incinerators. Environmental Pollution, 158(5): 1595-1602.

Wang M S, Chen S J, Huang K L, Lai Y C, Chang-Chien G P, Tsai J H et al., 2010b. Determination of levels of persistent organic pollutants $(\mathrm{PCDD} / \mathrm{Fs}$, PBDD/Fs, PBDEs, PCBs, and PBBs) in atmosphere near a municipal solid waste incinerator. Chemosphere, 80(10): 1220-1226.

Wang X, Ren N Q, Qi H, Ma W L, Li Y F, 2009. Levels and distribution of brominated flame retardants in the soil of Harbin in China. Journal of Environmental Sciences, 21(11): 1541-1546.

Wei H, Aziz-Schwanbeck A C, Zou Y H, Corcoran M B, Poghosyan A, Li A et al., 2012. Polybromodiphenyl ethers and decabromodiphenyl ethane in aquatic sediments from southern and eastern Arkansas, United States. Environmental Science and Technology, 46(15): 8017-8024.

Xu J, Gao Z S, Xian Q M, Yu H X, Feng J F, 2009. Levels and distribution of polybrominated diphenyl ethers (PBDEs) in the freshwater environment surrounding a PBDE manufacturing plant in China. Environmental Pollution, 157(6): 1911-1916.

Zhang W H, Wu Y X, Simonnot M O, 2012. Soil contamination due to e-waste disposal and recycling activities: A review with special focus on China. Pedosphere, 22(4): 434-455.

Zhao Y X, Qin X F, Li Y, Liu P Y, Tian M, Yan S S et al., 2009. Diffusion of polybrominated diphenyl ether (PBDE) from an e-waste recycling area to the surrounding regions in Southeast China. Chemosphere, 76(11): 1470-1476.

Zhou P, Lin K F, Zhou X Y, Zhang W, Huang K, Liu L L et al., 2012. Distribution of polybrominated diphenyl ethers in the surface sediments of the Taihu Lake, China. Chemosphere, 88(11): 1375-1382. 